\title{
Proyecto de Restauración del Quiosco de Música del Paseo del Bombé en el Parque de San Francisco de Oviedo
}

Clara Rey-Stolle Castro

Arquitecto

Por encargo del Ayuntamiento de Oviedo se elabora el Proyecto Básico y de Ejecución de restauración del Quiosco de Música del Paseo del Bombé de fecha julio de 2013, ubicado en el Parque San Francisco de la ciudad de Oviedo, que tiene por objeto la restauración del quiosco así como el Anexo del Estudio de Recuperación del alero y elementos singulares que configuraban la cubierta original, de fecha abril de $2014 .^{1}$

Restaurar es reinstaurar, recomponer tanto la obra portante como su ambiente, a fin de que pueda ser gustada, o al menos degustada, por los nuevos visitantes. En la base de la restauración deberá pues existir un profundo conocimiento, no sólo de la técnica con que se construyó la obra a restaurar, sino de las leyes arquitectónicas, muchas veces no escritas, aunque casi siempre construidas y legibles en los edificios coetáneos. Se insiste igualmente en la recuperación o rehabilitación del uso de la propia arquitectura, ya que en la base de una arquitectura recuperada se encuentra una búsqueda de los usos que dicha edificación podría soportar y favorecer. ${ }^{2}$

\footnotetext{
Con respecto a la legislación vigente, el Quiosco se encuentra sujeto a una protección patrimonial y urbanística. La protección patrimonial se deriva de su inclusión en el Catálogo Urbanístico del Plan General de Ordenación Urbana de Oviedo (BOPA 25 de marzo de 2006), con el grado de Protección Integral Singular. Previo a la elaboración del proyecto definitivo se hizo necesaria la aceptación de los criterios de actuación en la recuperación del alero, tanto por parte del Servicio de Patrimonio del Ayuntamiento de Oviedo, como de la Consejería de Educación y Cultura; así como la autorización expresa de dicha Consejería al proyecto integral.

2 Quiero hacer constar mi agradecimiento a José Ramón Alonso Díaz -arquitecto técnico-por su colaboración en el proyecto, a Mercedes Sánchez Arbesú -Responsable de la Sección de Edificios y Patrimonio Municipal-, Ana Ma Herrero Montero -Jefe del Archivo Municipal- y Ma Jesús Villaverde Amieva del Real Instituto de Estudios Asturianos.
} 
1ª PARTE: ANÁLISIS HISTÓRICOARQUITECTÓNICO.

Reseña del medio físico, natural y geográfico. Evolución del Campo de San Francisco

El Campo de San Francisco, popularmente conocido como el Campo por los ovetenses, es un parque de 9 ha situado en el mismo centro de la ciudad de Oviedo, considerado como uno de los lugares más significativos de la capital del Principado de Asturias y auténtico pulmón de la ciudad.

La primera referencia sobre este antiguo bosque se remonta al siglo XIII según escritura conservada en la Catedral de Oviedo por la que D. Fernán Alonso, canónigo de la Colegiata de San Pedro de Teverga, realiza la donación de una fuente y un prado a la Orden de Frailes Menores de Oviedo. La fundación de un monasterio franciscano en estos terrenos dio origen a un primer núcleo monástico siendo el conocido "Campo" el propio huerto de dicho convento. Los frailes de San Francisco de Oviedo realizaron una serie de reformas en el siglo XIV como la canalización de aguas y el establecimiento de caminos de acceso.

La importancia social que el Convento y la Iglesia de San Francisco irán adquiriendo en los siglos siguientes será determinante para que, poco a poco, al apelativo de El Campo se le una el nombre del patrono del convento a la hora de especificar esta zona boscosa y praderías que se extienden fuera de la cerca que circunda el casco urbano por su salida hacia Galicia, situadas junto al monasterio (s XVI), quizás para distinguir esta zona rural de la situada más al Oeste, conocida hasta el presente siglo con el nombre de Campo de la Lana.

Siendo ya desde antiguo considerado como el más agradable paseo de la ciudad por personajes como Jovellanos, es en 1776, al finalizar las obras del Paseo de Chamberí -actual Avda. de Italia-, cuando cobra, según la intención ilustrada, carácter de espacio ordenado de $\mathrm{Pa}-$ seo. De esta fecha proviene la Silla del Rey.

Tras la desamortización de Mendizábal en 1816 los terrenos citados vinculados a huerto y jardín del convento franciscano pasan a manos del Municipio. En 1833 con motivo de la coronación de la Reina Isabel II se decide crear el Salón Bombé, comenzando así a configurarse como auténtico Parque Urbano. Entre 1853 -con la apertura de la calle Sta. Susana- y
1910 -con la de Marqués de Santa Cruz-, queda perfectamente acotado el espacio del actual parque. La integración del Jardín Botánico en el mismo se lleva a cabo en 1871, pasando a manos del propio Ayuntamiento.

A finales del XIX, el Campo fue objeto de numerosas intervenciones que tuvieron al arquitecto municipal Juan Miguel de la Guardia y Ceinos como proyectista principal. Consistieron en la apertura de nuevos caminos que se fueron ensanchando cada vez más, la introducción de varias zonas ajardinadas en el entorno del lago, construcción de escalinatas, fuentes secundarias o la ordenación del Salón Bombé. Hubo en las décadas finales del siglo una verdadera fiebre de situar allí quioscos y pabellones de madera e incluso cines y teatros, desapareciendo con el tiempo los que eran de arquitectura efímera.

La forma actual, fruto de la superposición en el tiempo de múltiples procesos de transformación, resulta con su trama de diagonales entrecruzadas, en su aparente inacabamiento, de una paradójica contemporaneidad formal.

\section{Estudio de la evolución del entorno. Paseo del Bombé}

Situado en la parte alta del Parque, cercano al paseo de los Curas $^{3}$, su nombre afrancesado hay quien lo relaciona con la estancia en Oviedo de las tropas napoleónicas al establecerse este como paseo en 1833 sólo veinte años después de la ocupación, ejecutándose a partir de 1835-36. En 1875 se inauguró la "Fuentona", y en los años siguientes las fuentes de "las Ranas" y "el Caracol".

El proyecto de El Bombé consistió en acondicionar un paseo enarenado con una longitud total de casi 170 metros, desde el Paseo de Chamberí hasta la calle del Rosal, hacia su centro. Para ejecutar la obra fue necesario enajenar parte del prado del convento de San Francisco y fincas posteriores particulares. El paseo se embellecería con un arco triunfal, canapés, esculturas, tres escalinatas y vallado lateral, rematándose con el ajardinamiento de parterres y plantación de carreras de álamos. La idea se completa con la

El Paseo de los Curas, situado junto al Bombé, entre este y la calle Santa Susana, debe su nombre centenario a estar relacionado con ser el lugar preferido por los clérigos para sus paseos al estar ubicado en discreto lugar pero próximo al festivo Bombé del que se escuchaba su música y conciertos. 


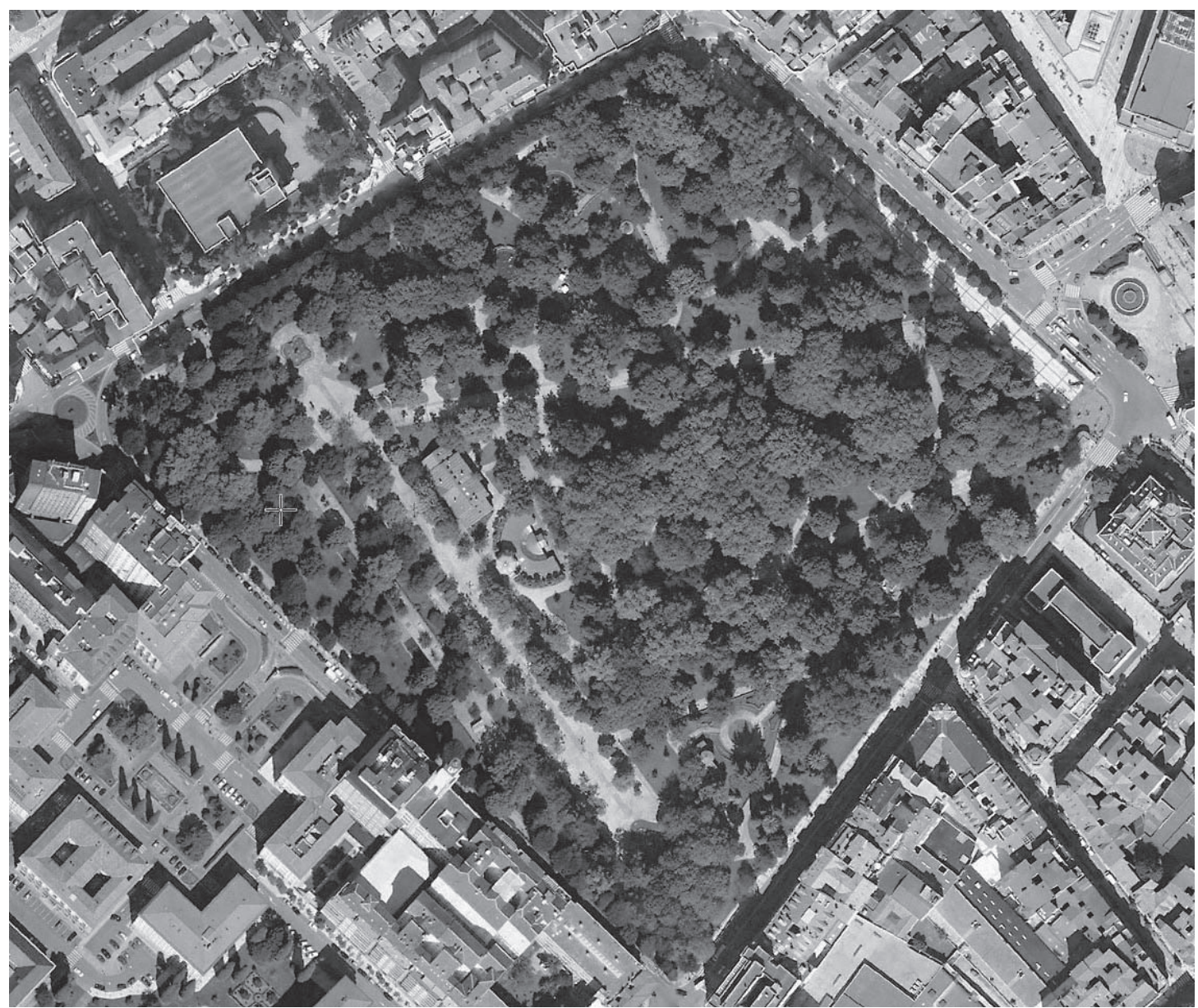

Fig.1. Fotografía aérea del Campo. En el proceso de conversión en suelo urbano de los terrenos rústicos, huertas y edificios de los franciscanos de Oviedo, se salvarían una amplia parcela de lo que en su momento había configurado un magnífico bosque que quedó bastante limitado hasta ocupar la actual superficie trapezoidal que se encuadra entre las calles Uría, Santa Cruz, Santa Susana y Conde de Toreno. El Campo de San Francisco pasó a ser el verdadero parque y zona de expansión y ocio de Oviedo.

decisión de bautizar al nuevo paseo con el nombre oficial de "Princesa Isabel".

El proyecto de urbanización, los adornos y elementos decorativos, el diseño y disposición de parterres, la elección de las especies vegetales -finalmente a base de castaños de indias-o el propio concepto de la obra ${ }^{4}$ y el nombre popular que terminará imponiéndose: "Bombé", indican claramente la influencia que, en aquellos momentos, ejercían los jardines del Palacio de Versalles, diseñados por André Le Nôtre (1613- 1700), considerados los más suntuosos, elegantes y bellos de su época y conocidos universalmente. La moda versallesca será moneda común en el diseño de parques y jardines duran-

Finalmente se acondiciona un Salón, al modo versallesco, caracterizado por ser un espacio de esparcimiento y reunión donde las grandes familias acuden a exhibirse. te todo el siglo XVIlI y XIX, y el Campo de San Francisco no será una excepción, al menos en la apertura y urbanización de paseos y avenidas, si bien se mantiene el aspecto boscoso y natural de la zona verde.

Posteriormente a la construcción del Paseo del Bombé, los jardines contaron con la incorporación del Quiosco de la Música. Se trata de una iniciativa con origen en el siglo XIX, cumpliendo con los cánones de esta tipología, que da solución al desnivel existente entre los dos paseos a los que da frente, con la construcción de un muro de contención y un terraplén, con forma de herradura que dará nombre al paseo inferior. La comunicación peatonal entre ambos paseos se ejecuta mediante rampas a ambos lados siguiendo la misma traza. Se configura de este modo desde un inicio un espacio inferior central al que parece "abrazar" el propio templete, y donde se instaurarán con el tiempo actuaciones musicales. 


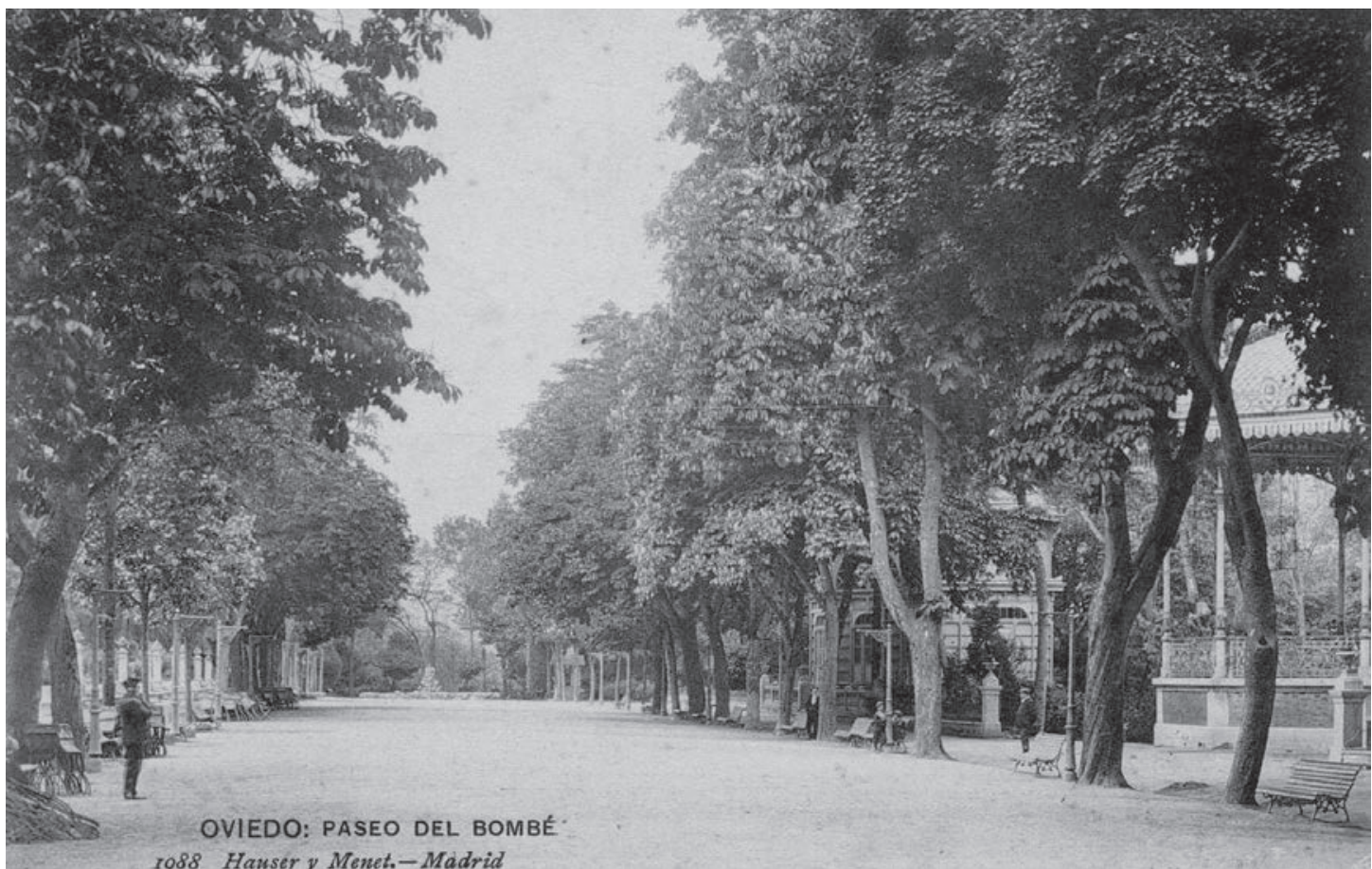

Fig. 2. El Paseo del Bombé con el Quiosco de Música, 1988. Tarjeta postal. Anv. Oviedo. Hauser y Menet. Rev. manus. Sta. Balbina... Autor Hauser y Menet. Fecha c. 1908. Fuente: Archivo del Museo del Pueblo de Asturias.

\section{El Paseo de la Herradura y el Aguaducho del Pavo Real}

Con respecto a las transformaciones más importantes del entorno, en épocas más recientes, éstas tienen lugar en el paseo de la Herradura. En 1992, el Ayuntamiento convocó un concurso de ideas para la instalación de un bar-cafetería de lujo en la plazoleta del paseo de la Herradura, el mismo lugar donde, unas décadas antes, se celebraban bailes durante las fiestas de San Mateo. Bajo el quiosco de música estaban el almacén y los aseos públicos. El proyecto ganador es presentado, bajo el lema "Pavo Real", por el hostelero Fernando Martín, regente del restaurante Trascorrales, y el boceto arquitectónico viene firmado por los profesionales Jose Antonio Fernández y José Bárcena. Se planteó la construcción de un edificio con marquesina, que bautizaron como 'Pavo Real', por imitar los colores y las formas de la exótica ave, realizado, fundamentalmente, en hierro, aluminio y cobre. Rodeándolo, un espacio polivalente al aire libre y una pérgola, ya pegando al quiosco de música.

A principios de 1995 el local es cedido a la Asociación Empresarial de Hostelería del Principado, haciendo que se plantee la ampliación del edificio original siguiendo una configura- ción radial, englobando los bajos del quiosco. Esta ampliación se concibió en su día como un edificio desmontable.

Sin embargo el cierre acometido, además de desvirtuar el concepto del proyecto original del propio aguaducho con la pérdida visual de su amplio alero, acomete contra la fachada del Quiosco de la Música, ocultándola en este frente e impidiendo el paso a los bajos del mismo.

Como producto de estas transformaciones el quiosco de música ha dado la espalda a dicho paseo presentando un único frente, el de la escena y acceso desde el Paseo del Bombé, que en este punto se dilata, unificándose sus calles en un amplio espacio que sirve de antesala al propio templete. Por todo ello actualmente se detecta escasa representatividad de la fachada al Paseo de la Herradura, así como patologías derivadas de la falta de mantenimiento de dicho edificio adosado.

\section{ANÁLISIS TIPOLÓGICO-ARQUITECTÓNICO}

El ocio y la aproximación a la naturaleza.

A partir del mayor interés por las cuestiones de la naturaleza, la sociedad del XIX producirá su propio modelo de espacio verde, parque, paseo, etcétera, como ya lo había generado la 

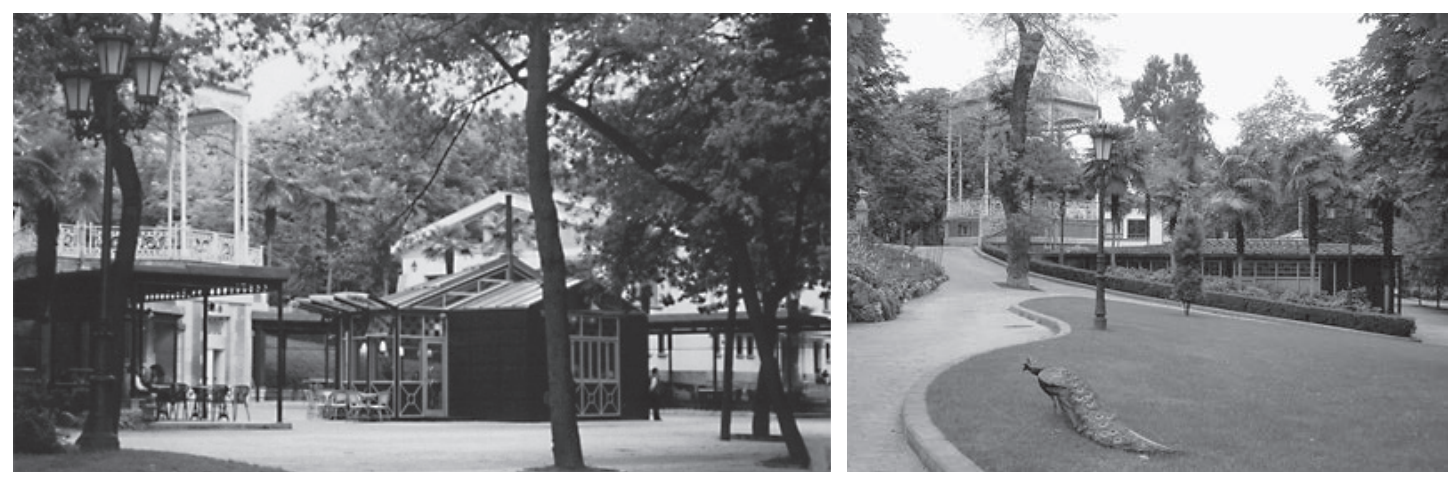

Figs. 3 y 4. Imagen del estado original del pabellón (izquierda) y transformación posterior del pabellón en su estado actual (derecha).

del XVIII. Las actividades vinculadas al paseo al aire libre experimentan un importante crecimiento, así como las infraestructuras urbanas correspondientes. Destaca, como ya se ha comentado, un tipo de implantación en el Campo de San Francisco, por su antecedente tipológico en los salones barrocos: el Salón del Bombé. Podría decirse que constituye la primera operación de sistematización de dicho Campo, convertido hoy en el Parque principal de la ciudad. ${ }^{5}$

Estos lugares serán "amueblados" mediante la incorporación de fuentes o farolas de alumbrado, etc. y que, en unión de una serie de arquitecturas, actuarán como elementos caracterizadores de dichos espacios. Del grupo de estas arquitecturas destacarán los quioscos de la música, en clara continuidad con el cultivo de la misma y su representación en espacios colectivos cubiertos, y los invernaderos, vinculados a la aproximación científica a la naturaleza, ambos especialmente ligados a las tipologías específicas de la arquitectura del hierro.

Estos edificios poseen una cualidad que les hace todavía hoy en día especialmente interesantes y es la posibilidad de manipulación del espacio a partir de la disponibilidad de la luz.

\footnotetext{
El término "Bombé" se repite en otros espacios de paseo localizados en otras ciudades asturianas, tales como Gijón (actual paseo del muelle, calle Juan Alvargonzález) o en Avilés. En cuanto al origen de esta denominación, probablemente la toma del nombre de un coche de caballos tipo charré, y la razón podría estar en el hecho de que por estos espacios pudieron desplazarse inicialmente este tipo de vehículos (al menos, en la disposición de dos andenes laterales y una gran avenida central podemos adivinar una cierta especialización funcional). Proviene del término francés "voiture bombeé", aplicado a un vehículo combado de dos ruedas y otros tantos asientos abierto por delante. Con tal denominación se hace alusión al concepto burgués del nuevo salón.
}

También su hipotética posibilidad de desmontaje y traslado añadirá la condición versátil, que permitirá el cambio de ubicación e incluso de utilización. Una cierta condición efímera, que les dará siempre su naturaleza provisional, será otra de sus características. Estas cuestiones, en la línea del proceso de la Revolución Industrial, tuvieron su importancia traídas de la mano del espíritu utilitarista de la época.

\section{Estudio de la tipología constructiva de los} quioscos de música

El templete o quiosco de música vendría a ser un pequeño capricho arquitectónico al margen de la ingeniería y casi de la propia arquitectura, si no fuera porque el nombre de muchos arquitectos municipales aparece vinculado a ellos, obligados por su oficio. Prácticamente no aparecen citados los quioscos en ningún tratado importante de arquitectura, muy esporádicamente en los de carpintería metálica y sí en cambio en los de cerrajería, llamados de serrurerie d'art. Ello nos da una idea de su consideración como obra menor, al entender el quiosco de música como un producto fabricado en serie e incluido para su oferta en el Catálogo de las casas de fundición y talleres de cerrajería.

Aunque existen muchas variantes, el quiosco-tipo consiste en una sencilla construcción festiva, característica del siglo XIX y principios del siglo XX, muy abierta, simétrica con relación al eje central (forma panóptica) y de planta poligonal y casi siempre ochavada, que consta de un zócalo, del que el piso más o menos elevado forma la escena que debe de cumplir con los requisitos acústicos, mientras que proporciona el abrigo necesario para el tiempo variable. Sobre dicho zócalo de fábrica de un 


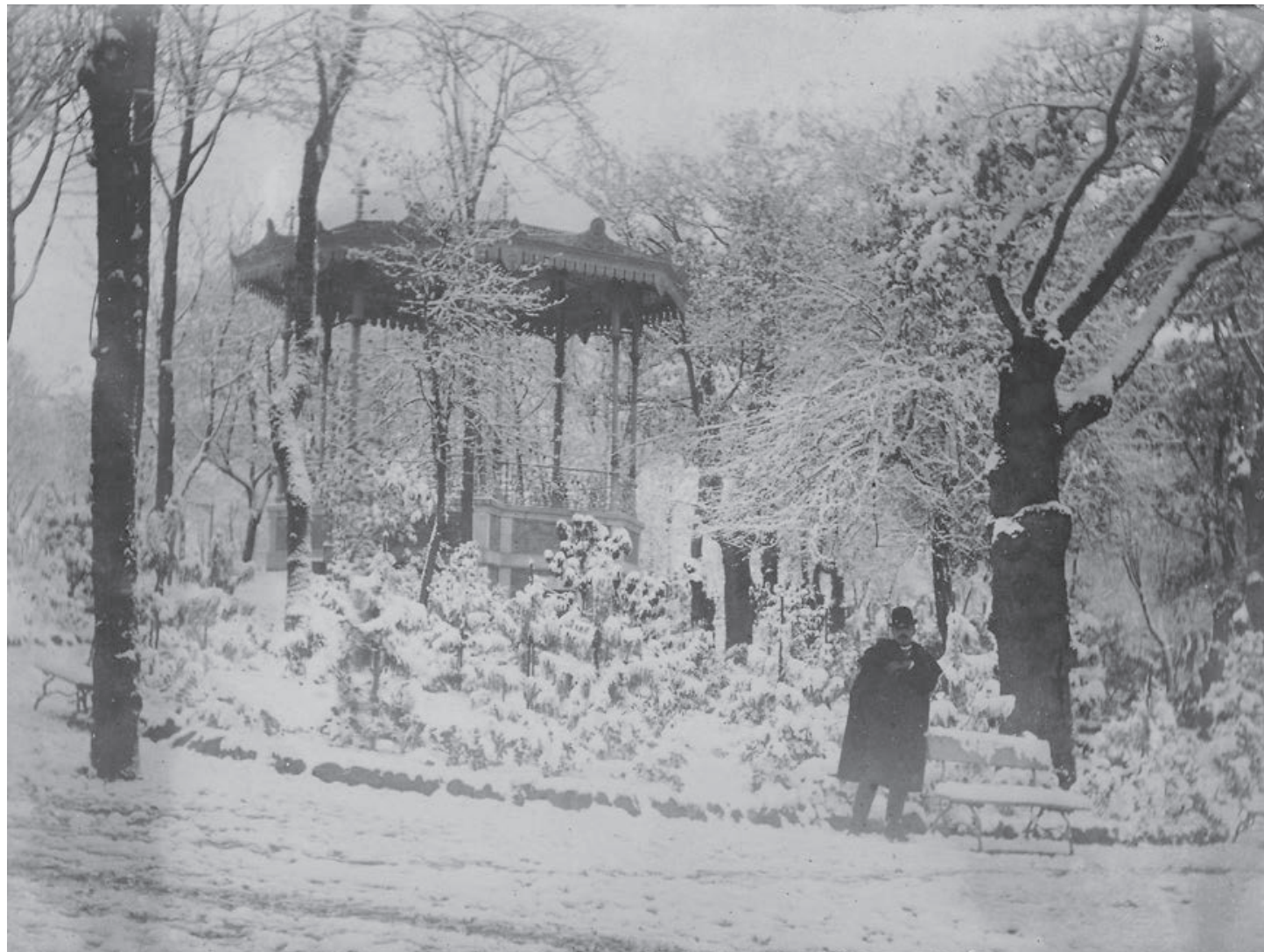

Fig. 5. Retrato de un hombre posando en el parque San Francisco nevado, delante del quiosco de música. Oviedo. Asturias. Autor Anónimo. Fecha h.1890. Fuente: Archivo del Museo del Pueblo de Asturias.

metro o metro y medio de altura, se levanta la estructura metálica a base de finas columnillas de fundición que soportan la cubierta con su vuelo correspondiente, resultando el conjunto una obra ligera y diáfana. Sobre este esquema caben múltiples variantes en cuanto al tratamiento de la escalera, los antepechos, las columnas de los remates, así como a la incorporación de fuentes, bancos, iluminación, etcétera, si bien eran relativamente sobrios en cuanto a su ornato.

Generalmente se trata de pabellones abiertos por todos sus lados, que entre otros usos han servido tradicionalmente para celebrar conciertos populares. Su estructura es normalmente de madera o metal ${ }^{6}$, cuyas columnatas llevan un techo en pabellón de escaso desni-

6 Se desconoce cuándo y cómo se produjo el salto diferencial del quiosco de jardín al de música, pero cabe pensar que al ser sustituidos los primeros de madera por los nuevos en hierro se perdieron los modelos sobre los que se produjo la evolución. No deja de sorprender que los quioscos férreos más antiguos que conocemos, todos del último cuarto de siglo XIX, aparezcan ya muy evolucionados en cuanto a la forma de la cubierta, vel. En cuanto a su sistema constructivo actual, presentan generalmente una estructura portante muy elemental, de hierro o pletina forjada, atornillada o roblonada, acompañada de una serie de elementos decorativos en pletina forjada, al igual que las barandillas, entre los que abundan las liras.

Enmarcando el estudio de los quioscos de música dentro de un contexto más amplio a escala urbana, tradicionalmente se liga su construcción a la evolución de las Plazas Mayores, durante el último tercio del XIX, "al ser cambiados sus solados por jardines o parques convirtiéndolos en "squares" con sus correspondientes árboles, bancos y kioscos de la música" ${ }^{7}$.

En este sentido, las plazas asturianas responden, más bien, al concepto de plaza medieval como ensanche en la trama viaria, producido en los accesos a los recintos amurallados

concebida como potente tornavoz y con volados aleros para recoger y proyectar el sonido.

Concepto de la Plaza Mayor desde el XVI hasta nuestros días; en "Morfología y Ciudad", Antonio Bonet y Correa. 

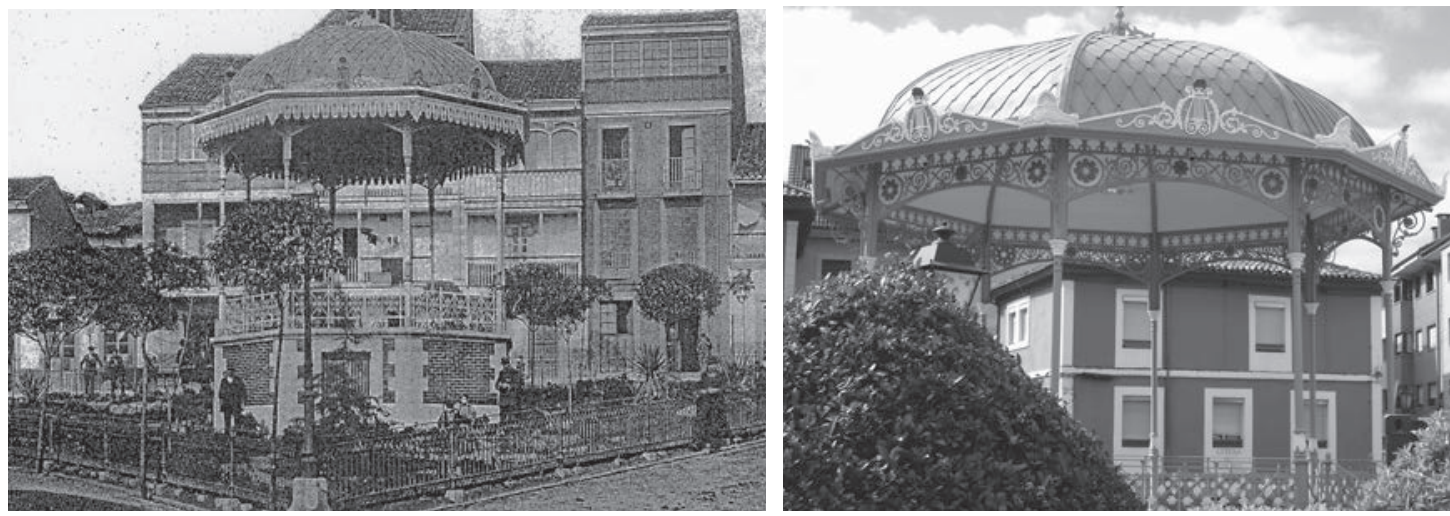

Figs. 6 y 7. Izquierda, la fotografía más antigua conocida del quiosco de Noreña, obtenida por 0. Bellmunt en 1897. Proyectado en 1892 por Juan Miguel de La Guardia, su tipología es prácticamente similar al de Oviedo, pero de proporciones más pequeñas y diseño menos cuidado, posiblemente por ir destinado a una población de menor importancia que la capital.

Derecha, Quiosco de música de Noreña, de 1892. Estado actual tras la restauración del 2013-2014 (Fotografía del autor).

o bien al encuentro de caminos, y en las que la regularización del tejido, en algún caso, se ha limitado a uno de los lados, como sucede en las plazas de los ayuntamientos de Oviedo y Avilés. Esta ausencia de plazas mayores, en unos casos, o de logar alcanzar ese uso de espacio público principal de la ciudad, en otros, se concretan en el caso asturiano en la voluntad de poseer un parque público representativo de la ciudad. Estos parques nacidos de circunstancias diversas -como desamortización, cesión particular, etc.- se convertirán en los espacios públicos por excelencia y, lógicamente, será en ellos donde se situarán los quioscos de música, centro de los bailes populares, requisito indispensable de las romerías y festejos y que se convierten en pieza singular del espacio público generado a finales del XIX.

Los quioscos aparecen pues en medio de los parques subidos en sus podios de piedra o ladrillo, como grandes "paraguas o medusas con patas de hierro", en donde las columnas de fundición sostienen unas cubiertas más o menos sofisticadas, recubiertas en su parte exterior por escamas o láminas de zinc, y en su interior, por tablas de madera. Pocas serán las ciudades o villas en que este símbolo de vida festiva no exista.

En una investigación tipológica realizada sobre este tipo de construcciones se recogen doce ejemplos en el territorio asturiano, de los que se conservan diez . Todos mantienen unas constantes tipológicas y constructivas, aunque

\footnotetext{
"La arquitectura del hierro en Asturias", J.R. Fernández Molina, J. González Moriyón. C.O.A.A., Oviedo, 1994.
}

los resultados formales y arquitectónicos son muy dispersos. En este sentido resulta significativo comprobar que, al contrario de lo que sucede con la arquitectura de los pabellones, los quioscos, por modestos que sean, se construyen en hierro, bien por voluntad de permanencia o por la búsqueda de una imagen siempre identificada con la construcción metálica.

Por una parte, los quioscos de Vegadeo, Castropol y Luarca, en el occidente de Asturias, se caracterizan en general por la sencillez decorativa y conceptual, con cubierta en pirámide octogonal apoyada en vigas de celosía situadas en las aristas de la misma.

Igualmente con ciertas semejanzas formales se agrupan los quioscos de Oviedo, Noreña y Grado. El elegante quiosco de la música de Oviedo, proyectado en 1888 por Juan Miguel de La Guardia, servirá de referencia a los construidos en las dos ciudades próximas, Noreña y Grado, con mayor modestia. Su novedosa solución de cubierta en bóveda de ocho paños, cuyas aristas son arcos rebajados, es utilizada por el arquitecto casi miméticamente en el caso de Noreña. Salvo la reforma que se acomete en la primera mitad del s XX, desmontándose el "lambrequín que colgaba de la cornisa", se

\footnotetext{
En 1913 se introducen importantes reformas en los jardines de la Plaza Mayor y en el quiosco: "En el quiosco se procede a anular el lambrequín que colgaba de la cornisa para dejar más a la vista la arquería de arcos rebajados, con lo que se intentaba quitarle pesadez y dar mayor embellecimiento a la construcción. Esta reforma vino impuesta por la estética modernista de la época; lo que imitaron otras poblaciones españolas, como fue el caso de Oviedo con El Bombé". José Manuel Fanjul Cabeza. «Datos históricos del concejo de Noreña».
} 
conservan en este quiosco el resto de los elementos originales de cubierta.

Como casos singulares destacan el quiosco de la música de Avilés de 1894, junto con los de La Felguera, superponiendo a la habitual planta octogonal unas cubiertas fragmentadas en varios cuerpos, en las que la cúpula central adquiere todo el protagonismo, y que, en el caso de Avilés, se completará con pináculos y tirantes de gran complejidad formal. Por otra parte, la proximidad a la estética modernista y secesionista en los primeros años del s XX, se hace patente en la original forma de diseño de las columnas (de perfiles livianos, uniones roblonadas y piezas singulares) de los quioscos de La Felguera y Sama.

El Quiosco de Música del Bombé. Descripción arquitectónica

Este Quiosco de Música, situado en el Paseo del Bombé - eje occidental del Campo de San Francisco-, fue construido a instancias del Ayuntamiento, destinado a ofrecer conciertos de música a los ovetenses, y diseñado, por tanto, con el propósito de acoger a la banda municipal.

Levantado sobre el talud del lateral izquierdo del Bombé, unos metros antes de la Fuente del Caracol, se concibe como un templete elevado sobre un podio de piedra, de planta octogonal, que salvaba el desnivel del paseo del Bombé con el inferior de la Herradura. Firma el boceto del proyecto el arquitecto municipal Juan Miguel de la Guardia y Ceinos ${ }^{10}$ el 27 de

10 El arquitecto Juan Miguel de la Guardia y Ceinos (1859-1910) estudió arquitectura en Madrid y obtuvo la plaza de arquitecto municipal de Oviedo en 1882. Fue uno de los representantes más genuinos de la arquitectura de Asturias a finales del s XIX y comienzos del XX, formando junto a Aguirre y Rivero la denominada generación de 1881 . Se trata de uno de los profesionales que más contribuyeron a definir la imagen del ensanche de la ciudad de Oviedo en el cambio de siglo, como diseñador del aspecto de la nueva ciudad burguesa. Junto a importantes obras de promoción privada -como las casas de Santos Rodríguez y Valdés, Uría y Milicias o el chalet de Concha Heres-, realizó numerosas obras públicas y de servicios de iniciativa municipal. Éstas tenían como objeto propuestas de amueblamiento urbano y destinos educativos y de ocio que se habían quedado obsoletos o que simplemente no existían: teatros, escuelas, mercados cubiertos, parques, fuentes, quioscos de música y pabellones de exposiciones van a configurar la mayor parte de las obras de iniciativa pública. Desde el punto de vista arquitectónico, De la Guardia se inscribe dentro de un enero de $1887^{11}$, siendo aprobada la construcción el 3 de septiembre de aquel año. Se adjudica la construcción a Doroteo Manteola en subasta el 22 de marzo de 1888, inaugurándose un año más tarde. Su estructura y elementos de fundición fueron construidos por Arturo Bertrand Renard, en la empresa Fundición y Construcción Bertrand (que ejecuta igualmente el de Noreña).

El templete de música, como es característico de este tipo de construcciones consta de tres partes fundamentales: basamento -usado como almacén y aseos públicos-, columnas y cubierta; siendo también una característica común los materiales utilizados en cada una de las partes: piedra y ladrillo, hierro fundido, zinc y madera, respectivamente. La fundición se usará además en las barandillas y celosías laterales de cerramiento, siendo el hierro forjado el empleado en las vigas de apoyo de cubierta y la armadura de ésta.

La principal novedad del Quiosco de Música de Oviedo será plantear la construcción de la cubierta mediante una bóveda de ocho paños, cuyas aristas son arcos rebajados. La cubierta abovedada se sostiene mediante columnas de hierro fundido de tónica clasicista con capiteles de tipo corintio y fuste estriado. La unión entre columnas se hace mediante arcos rebajados de fundición, cuyo interior se decorará con redondos y pletinas que siguen trazados geométricos y naturalistas, en algunos casos de referencias modernistas, produciendo a contraluz el efecto de bordados de puntillas.

Del techo colgaba una artística lámpara de ocho puntos de luz, alimentada por gas, como el resto del alumbrado del Bombé, sistema que será cuestionado en 1889 en un informe sobre el estado sanitario del Campo.

Este quiosco se vio privado de otro de los elementos que lo hacian especialmente atractivo: El proyecto de Juan Miguel de la Guardia y las fotos antiguas del mismo (que se adjuntan) nos muestran la existencia de un alero perimetral octogonal, del que colgaba un amplio lambrequín que en la parte superior dejaba paso a pequeños frontones con máscaras centrales, y que remataba adecuadamente la composición. De este modo la construcción aparece actualmente como incompleta.

eclecticismo contenido, entre el clasicismo que se acaba y el modernismo que llega.

11 A.M.O. 1-1-10-31. 

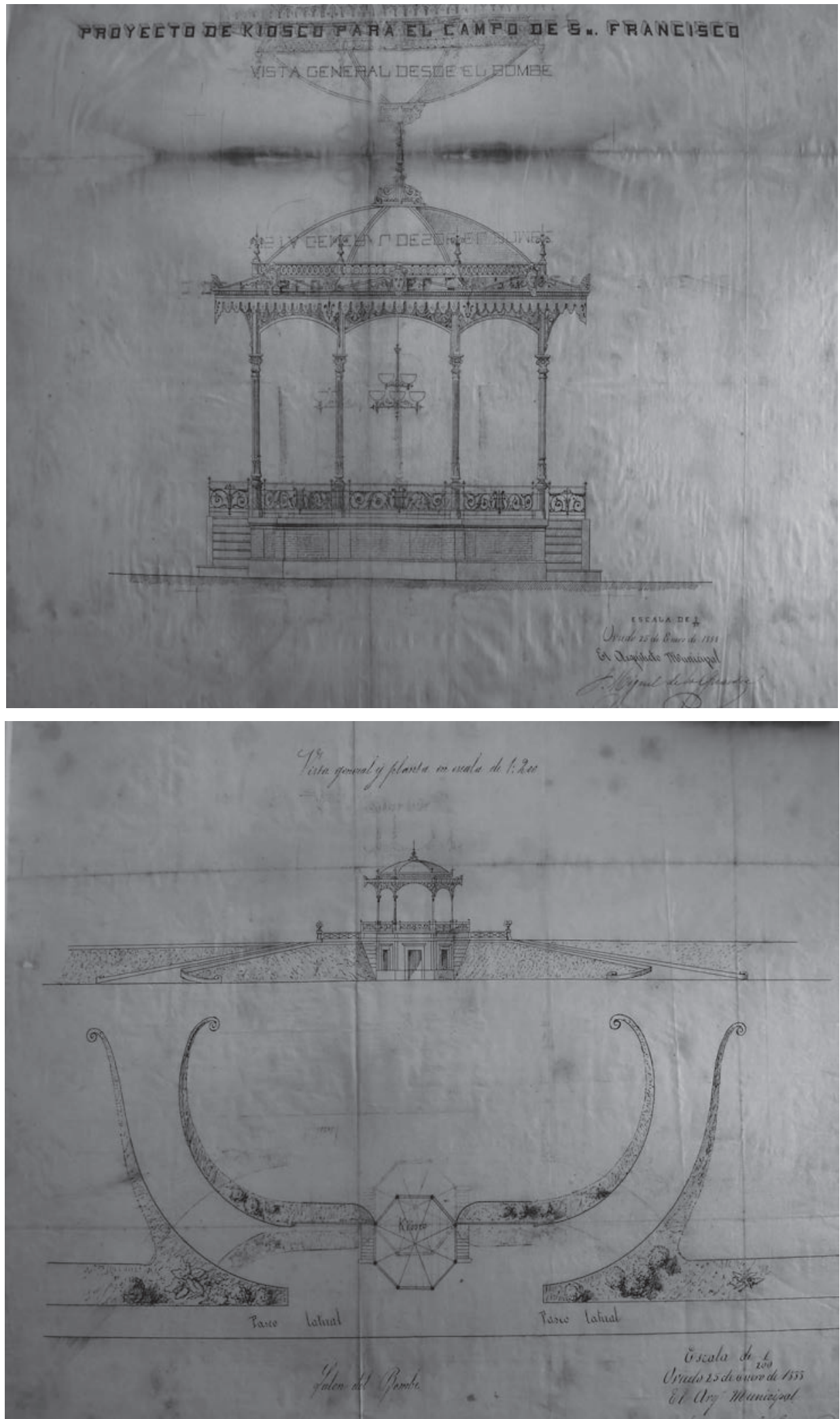

Figs. 8 y 9. Quiosco de música de Oviedo, proyecto de Juan Miguel de la Guardia y Ceinos. 25 de enero de 1888 ${ }^{1}$. Vista desde el Bombé, y vista general al Paseo de la Herradura y planta.

12 Archivo municipal de Oviedo. Legajo 10, documento 31 (contiene 3 planos firmados por el arquitecto J.M. de la Guardia) 


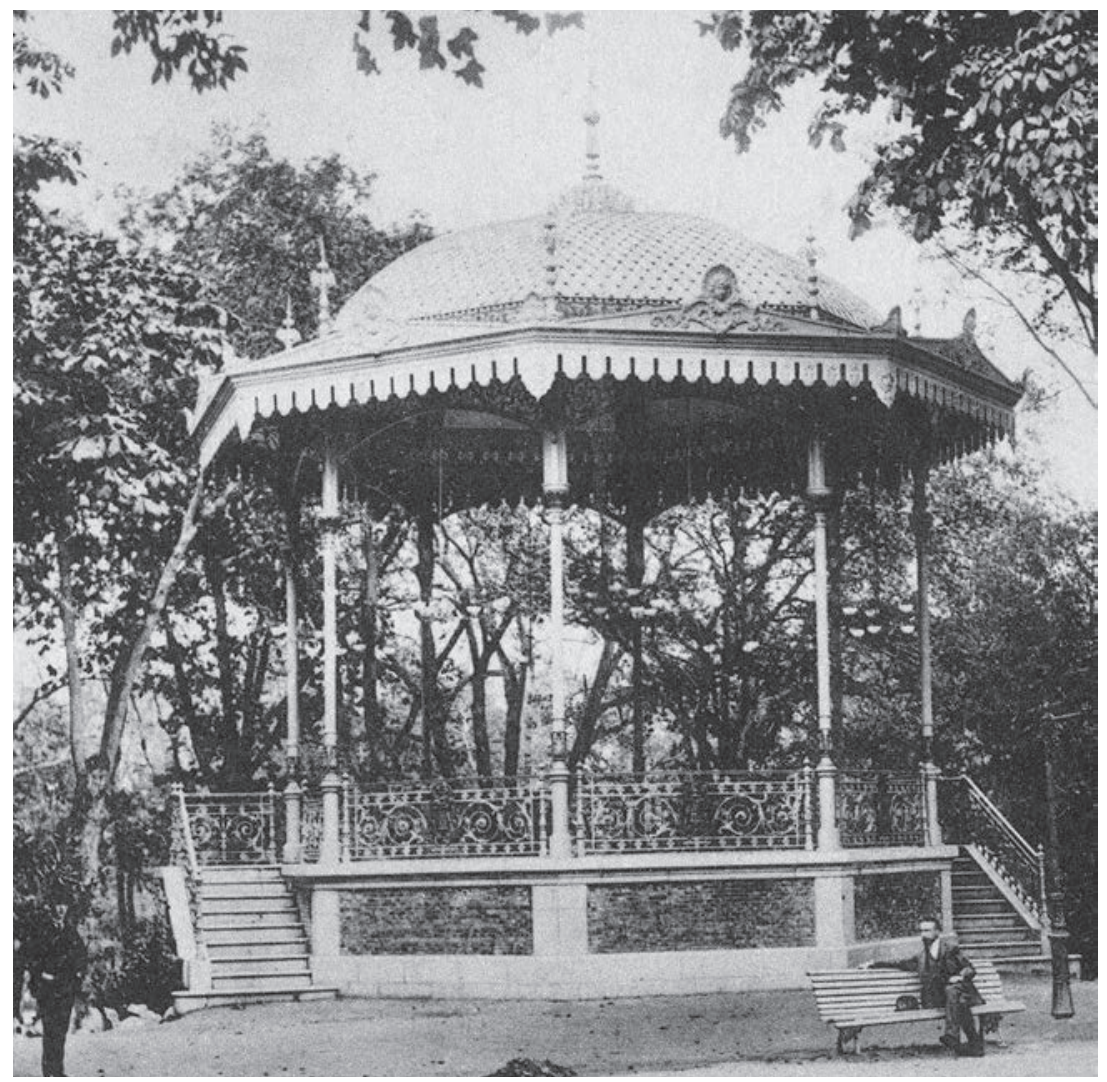

Fig. 10. Postal de 1902. Fuente: Archivo Municipal de Oviedo.

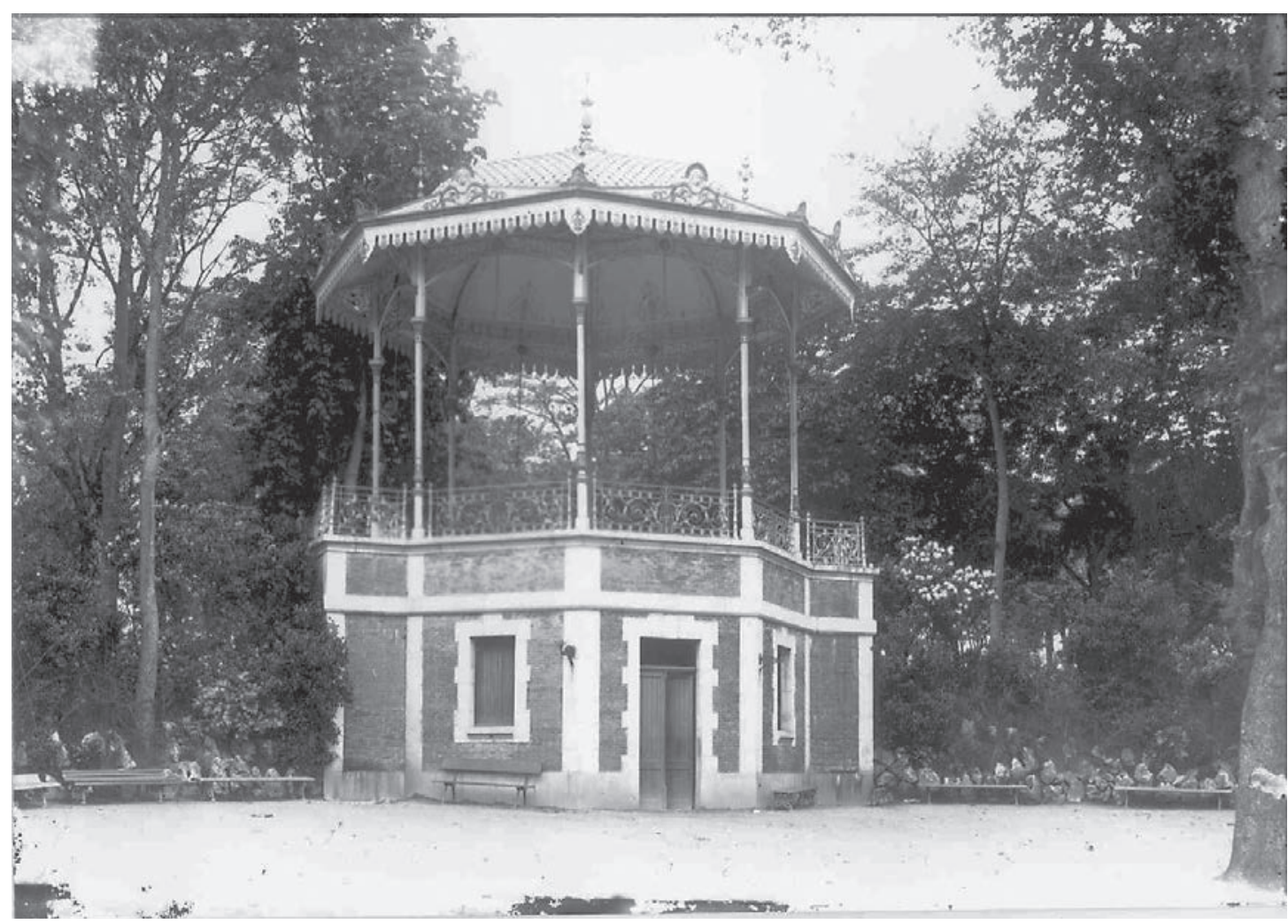

Fig. 11. Positivo de una placa de cristal, posiblemente del fotógrafo Luis Muñiz Miranda, h. 1920. Se aprecian las pinturas originales del intradós de la cúpula, con un supuesto revestimiento del tablero de madera mediante estuco decorado. Fuente: Archivo Real Instituto de Estudios Asturianos (RIDEA) 

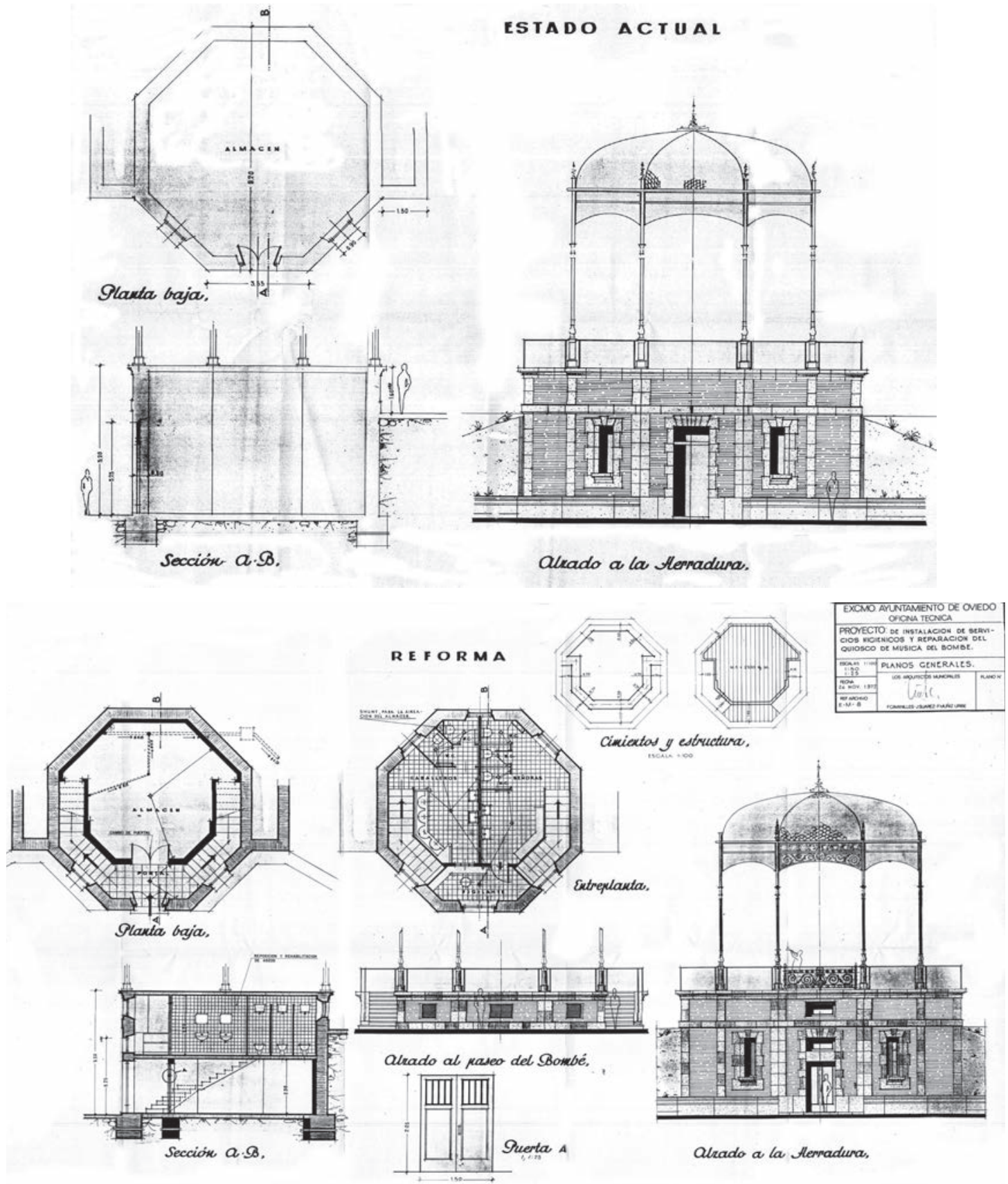

Fig. 12. Planos del proyecto de 1972. Estado actual y reformado. Fuente: Archivo Municipal de Oviedo.

Todo ello, si se va repasando el temario decorativo, es eminentemente ecléctico y nos recuerda los diseños del mismo De la Guardia para las barandillas del Teatro Campoamor ${ }^{12}$.

El basamento perimetral, es objeto de modificaciones posteriores, con la apertura de las

12 Las verjas de los antepechos incorporan alegorías musicales y se repiten las liras entre roleos.

Morales Saro, M.C.: Oviedo-Arquitectura y desarrollo urbano. Oviedo, 1981, pp. 125-126. ventanas para dar luz natural a los aseos que se sitúan en su interior, así como el adosamiento de la estructura de ampliación del edificio del 'Pavo Real'.

\section{Descripción del elemento constructivo del} alero y elementos decorativos:

Según proyecto original, y construcción primitiva del mismo, el quiosco de música 

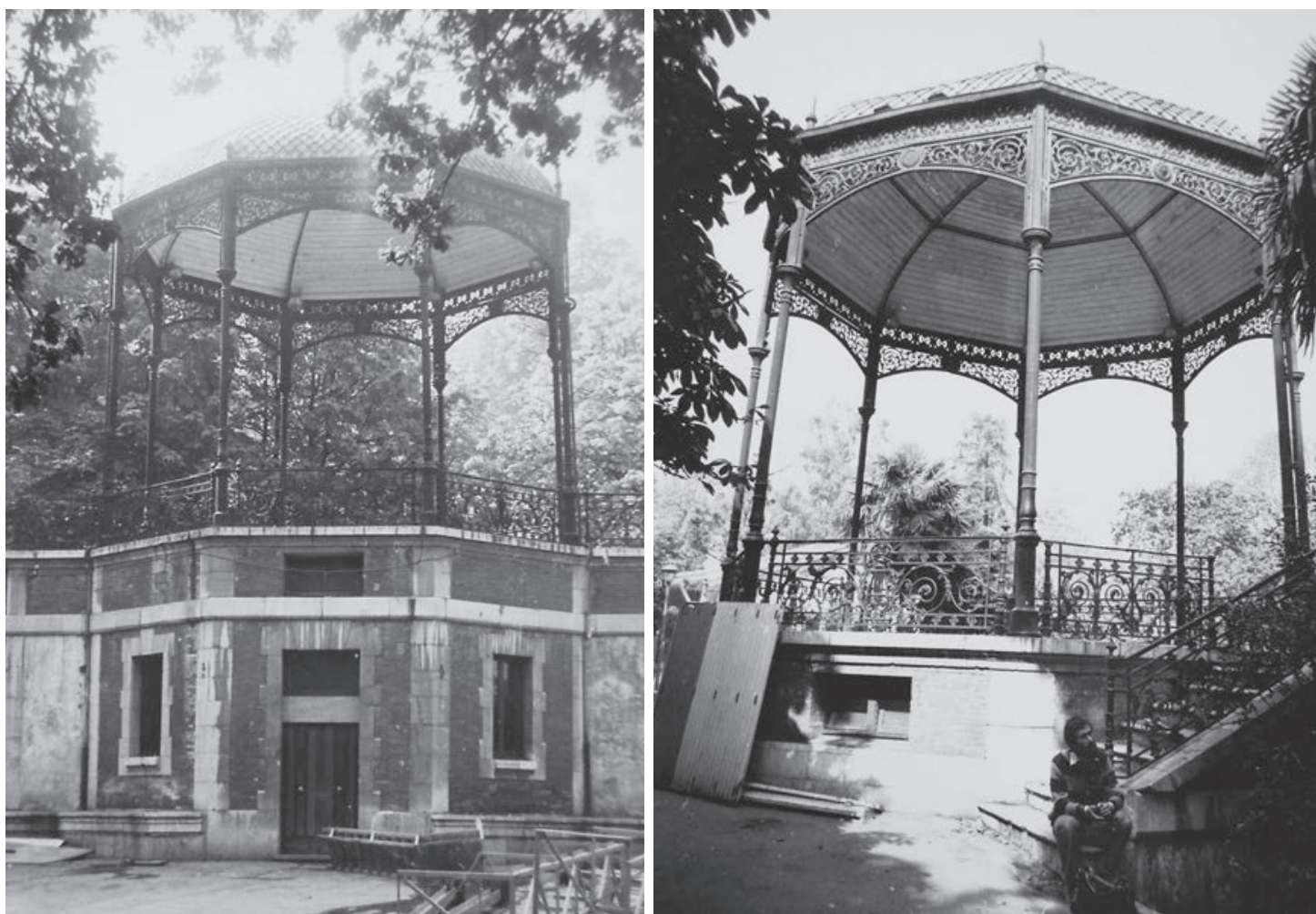

Figs. 13 y 14. Alzado al Paseo de la Herradura, y al Paseo del Bombé, año 1978. Archivo del P. Patac.

contaba con un alero de más de un metro de vuelo, rematado en cada paño mediante un frontón (frontis o frontispicio), elemento arquitectónico de origen clásico que consiste en una sección triangular, dispuesto sobre el entablamento o cornisa. Se caracteriza por una amplia decoración de los tímpanos con motivos alegóricos, vegetales y roleos, siendo acroteras o adornos igualmente de origen clásico dispuestos en el vértice (alegoría con cara estampada) o sobre las extremidades del frontón (piezas decorativas de ornamentación vegetal ubicadas en los extremos de los ejes del octógono), cornisa de perfil estampado con acabado inferior de remate de lambrequín estampado, cresta doble que unía las lanzas, membrones...., todos planteados en su ejecución en zinc con diferentes técnicas de cilindrado, repujado o estampado propias del año 1888. Sin embargo, en el caso del Quiosco de Música de Oviedo, se ejecutan finalmente en fundición, en la línea de los que todavía hoy en día pueden observarse en el Quiosco de Música de Noreña. Los motivos decorativos siguen la misma estética que los contenidos en las piezas de fundición de la estructura y cerramientos originales del quiosco, con la aparición de caras estampadas y roleos decorativos.
La evacuación del agua se realizaba mediante pequeñas gárgolas centrales a cada lado del octógono, conectadas con el canalón perimetral, en el interior del límite del colgante o lambrequín, por lo que no se evacuaba hacia el exterior del elemento. El canalón perimetral, sin pendiente, permanecía más hundido que la estructura de borde de fundición, lo que dificultaba la salida de agua de cubierta, con el consiguiente deterioro de toda la ornamentación y estructura. ${ }^{13}$

La estructura del alero se resolvía mediante unas ménsulas de hierro fundido decoradas atornilladas a los enanos de fundición existentes, y sobre las que apoyan los angulares y la tabla de cubierta.

Las lanzas ubicadas en los extremos de los ejes del octógono presentaban mayor altura que las actuales.

Completaba la cubierta un remate ornamental de pináculo central, ejecutado igualmente en fundición, que se conserva. ${ }^{14}$

13 Estas patologías se observaron, durante la redacción del proyecto, en el quiosco de música de Noreña.

14 Como ya se ha comentado en la primera mitad del s XX se acometan reformas, procediéndose a desmontar la totalidad del alero, por lo que solamente han llegado hasta nuestros días los elementos decorativos ubicados 

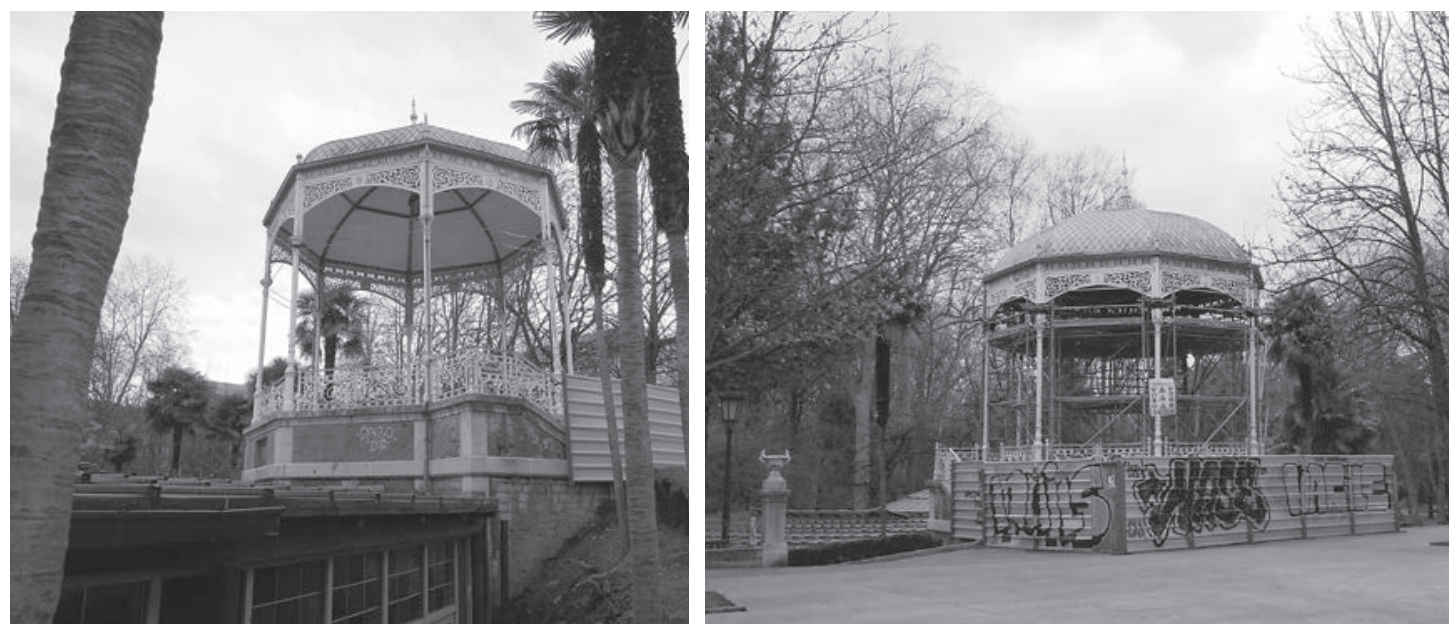

Figs. 15 y 16. Estado actual desde la subida al Bombé y vista desde el propio Salón Bombé.

Estudio de las Intervenciones y reformas

"Proyecto de instalación de servicios higiénicos y reparación del Quiosco de Música del Bombé, de 24 de noviembre de 1972".

Se trata de un proyecto redactado por la Oficina Técnica del Ayuntamiento de Oviedo en noviembre de 1972, y firmada por los arquitectos municipales F. Cavanilles, J. Suárez y F. Muñiz Uribe, consistiendo en la reforma de los bajos del quiosco, donde se habilitaron unos modernos aseos públicos.

El actual basamento se configuraba en un único volumen, iluminado únicamente por los ventanales practicados a nivel del acceso desde el Paseo de la Herradura. El proyecto añadió un forjado intermedio distribuyéndose el espacio en un portal del que arrancan dos escaleras laterales, adaptadas a la planta octogonal, de acceso a los aseos públicos situados en la entreplanta; en el espacio central de la planta baja se dispone un almacén destinado al departamento municipal de jardinería y sobre el espacio del portal un pequeño cuarto para el vigilante. Se modifican los alzados, con la apertura de 3 huecos de ventilación e iluminación en el zócalo existente al Paseo del Bombé, y otro sobre el acceso hacia La Herradura en este mismo cuerpo.

sobre la cúpula: pináculo central y arranque de las lanzas.
"Proyecto de reparación del Quiosco de la Música del Bombé" de Mayo de 1990

Posteriormente se lleva a cabo por la Oficina Técnica del Ayuntamiento de Oviedo, en 1990, una reparación del quiosco, con modificación de la planta de aseos. Según la memoria del mismo, el avanzado estado de deterioro de la cubierta de zinc aconsejó la sustitución de la madera del techo de la bóveda y la cubrición de zinc por otra de las mismas características, así como la restauración de las barandillas de fundición, reposición de lanzas, y restitución de plaqueta cerámica, entre otros trabajos.

Descripción de sistemas constructivos y materiales. Estado actual.

La estructura vertical del basamento se resuelve mediante ocho muros principales, o paredes maestras, de traza octogonal, dispuestos según los lados del polígono y arriostrados entre sí. Se trata de fábricas de aparejo irregular, de mampostería ordinaria, ajustados y trabados con mortero de cal. Se refuerza, para mayor solidez, mediante hiladas verticales de sillería de caliza azul tipo Naranco, formando lo que se denomina cadenas esquineras. Una imposta de cantería lisa divide la fachada a la Herradura en dos alturas, coincidiendo con el nivel del zócalo de la fachada al Paseo del Bombé, que resuelve sus entrepaños en "ladrillo fino de Valladolid“. El remate superior de los muros se realiza mediante una imposta moldurada, a modo de cornisa. 
A esta estructura portante principal, sobre la que se eleva la estructura de fundición que configura el templete propiamente dicho, se le adosan en ambos extremos unos muros de contención de mampostería concertada, sobre los que apoya la escalera exterior. El nivel superior de estos muros se ejecuta en ladrillo visto en aparejo de tizones o "a la española", con esquinales de cantería, dando continuidad a toda la estructura del basamento.

En la reforma de 1972 se añade un forjado cerámico intermedio con el fin de habilitar en la entreplanta unos aseos públicos, y un almacén en planta baja. El piso de la escena se resuelve igualmente con forjado cerámico y vigueta cerámica prefabricada. El forjado de la planta intermedia se apoya en un recrecido de los muros perimetrales de planta baja, en media asta de ladrillo macizo, y un muro de carga interior de citara de asta que sirve igualmente de apoyo de la escalera, con su correspondiente cimentación en hormigón armado. Este muro se refuerza por dos pilares de hormigón armado arriostrados al muro perimetral mediante sendas vigas planas de hormigón, ocultas en el forjado de la escena.

La estructura vertical del templete se resuelve mediante 8 columnas de hierro fundido, de fustes estriados y capiteles corintios, suplementadas en vertical mediante un enano de fundición. La unión entre enanos se hace mediante arcos rebajados de fundición, constituyendo todo ello un cerramiento perimetral de los lados del polígono con misiones de absorber empujes de las nervaduras, de articulación de las columnas, de arriostramiento y de decoración. Estos pórticos de fundición están constituidos por dos piezas, una viga superior de dimensión uniforme rectangular y otra inferior de sección variable a modo de faldón, ambos formados por dos elementos simétricos atornillados. Su unión al enano se resuelve mediante sistema atornillado al tresbolillo, resolviendo el ajuste mediante la introducción de forros de chapa entre ambas piezas.

Las ocho columnas de fundición, con una altura de $4.310 \mathrm{~mm}$ y fuste de sección anular de $\emptyset 140$, se ubican en los vértices del polígono, prolongadas en suplementos o enanos de 1.860 $\mathrm{mm}$ de longitud, enlazados mediante la interposición de un tubo interno de fundición y una pieza en "L" atornillada a la cabeza de la co- lumna y al propio enano. Sobre dichos enanos, apoyan las vigas curvas de cubierta, a través de una ménsula de fundición con dos orejetas ubicada en la propia cabeza del enano. La unión se ejecuta atornillada.

La estructura de cubierta se sustenta sobre ocho vigas metálicas dispuestas de forma radial apoyadas en su extremo sobre cada uno de los enanos y que acometen a un nudo central de cumbrera, formado por una clave decorada inferior que oculta la corona metálica de enlace mediante uniones atornilladas. Las vigas coinciden en dimensiones con un perfil IPN 120 y presentan la curvatura de la bóveda de cubierta.

La fundición se usará además en las barandillas perimetrales del quiosco de música y de la escalera de acceso al quiosco. Se conservan las barandillas originales del año de construcción del quiosco, aunque restauradas ${ }^{15}$. Al igual que las celosías y arcos rebajados, la ornamentación se centra en el interior de los elementos, que se decoran con redondos que siguen tazados geométricos combinando con roleos y motivos naturalistas en piezas macizas de estética vegetal, y otros que hacen referencia a la música, a través de una lira. Para su ejecución se han seguido distintas fases: Los redondos, de hierro dulce, se moldean en espiral, con la curvatura adecuada a cada tipología. Dicho redondo se introduce en los moldes de las piezas decorativas vegetales, fundiéndose todo junto, y obteniéndose una pieza única. ${ }^{16}$

La cubierta existente, a pesar del desmantelamiento del alero y posteriores restauraciones, sigue las líneas de la original del año 1888. Con aproximadamente $57 \mathrm{~m}^{2}$ de superficie cubierta, está resuelta con la geometría de la bóveda rebajada de ocho paños, mediante entablonado machihembrado de pino tea colocado a ras de la cara exterior de la estructura, cubrición de escamas estampadas de zinc y caballetes de zinc clavados sobre listones en remates de uniones de aguadas (sobre nervios). En la zona de desarrollo horizontal superior Se respetó la disposición original de planchas lisas de zinc. El mismo entablonado constituye el acabado visto de la cara interior de la cúpula. Entre am-

\footnotetext{
Se tiene constancia al menos de dos restauraciones, hacia 1970 y 1990.

16 Ésta misma técnica se plantea para la ejecución de las piezas necesarias de la presente restauración.
} 
bos componentes, madera y zinc, no se dispone de ningún compuesto celulósico prensado a modo bituminoso u otro elemento que cumpla la función de barrera hidrófuga. Estos elementos datan de la reforma de 1990.

Completa la cubierta, un remate ornamental de pináculo central, rematado con piezas radiales de roleos y elementos vegetales en su base, así como 8 lanzas ubicadas en los extremos de los ejes del octógono, todos ellos realizados en fundición. El pináculo central, original del año 1888, responde a moldes de la época. Las lanzas, ancladas directamente en el enano, conservan únicamente su base o arranque original en fundición, documentándose una restauración posterior en los años 70 y 90, pero de la que se desconoce el alcance.

Otra dificultad que presentaba el diseño original era la evacuación de agua de lluvia, procedente del plano de cubierta. El proyecto no contemplaba, como en otras tipologías similares de arquitectura del hierro, el ocultamiento de bajantes dentro de las columnas de hierro fundido, y la evacuación del agua, supuestamente mediante pequeñas gárgolas, se topaba también con los obstáculos de los propios elementos decorativos -como en el caso de las crestas dobles estampadas que unían las lanzas-.

\section{2a PARTE: DIAGNÓSTICO}

Del estudio del estado actual y patologías de materiales que componen el edificio se concluyó que:

Los desplomes y movimientos que presenta actualmente la estructura se deben a fallos de resistencia de la misma a causa de patologías, principalmente de oxidación y corrosión ${ }^{17}$, que originan aumentos de volumen de las piezas estructurales y de las pletinas intermedias, lo que hace que se produzcan tensiones y desplazamientos que en origen no existían. Así mismo, y dado el alto grado de corrosión alcanzado en los elementos férricos estructurales ocultos -llegando a la perforación del alma de las vigas curvas de cubierta y a la pérdida de sujeción de

17 En el caso de la corrosión la causa del daño es extrínseca a la estructura. La entrada de agua en los puntos de encuentro de las lanzas, sin solución de estanqueidad en la totalidad de la cubierta de zinc, parece ser, en un primer análisis, una de las causas del elevado grado de corrosión en estos nudos estructurales. los elementos que componen la estructura-, no se puede prever el comportamiento de la misma, ni garantizar su estabilidad.

Estas conclusiones se recogieron en un informe sobre la estructura metálica, presentado ante el Ayuntamiento, tras la revisión de la misma. Durante la ejecución del presente proyecto, como medida alternativa al desmontaje previo al inicio de las obras, y a petición del Ayuntamiento de 0viedo, se planteó un refuerzo de estabilidad alternativo, que se resolvió anclar al andamio interior planteado para la ejecución de la restauración.

El resultado final determinó la actuación de urgencia en la estructura de cubierta, con restauración de elementos de fundición así como la restitución de los perfiles de nervios de cubierta. Se valoró la reconstrucción del alero original, eliminado de la edificación por motivos desconocidos, estudiándose su posible incorporación al proyecto.

En cuanto a la recuperación de las piezas de hierro fundido que conforman la estructura vertical (columnas, enanos o suplementos, arcos y barandillas), se trata de elementos de fundición gris, con buen comportamiento frente a la corrosión (que se verifica como superficial), y buena resistencia al desgaste, presentando un aceptable estado de conservación, que permite su recuperación y restauración. No ocurre lo mismo con las piezas de hierro forjado que permanecían ocultas en parte y que forman el armazón de cubierta, así como pletinas o forros intermedios que es necesario reponer en su totalidad.

La necesidad de sustitución de los nervios de acero de cubierta obliga al levantamiento de la cubrición, y posterior sustitución de entablado de madera y acabado de escamas de zinc.

La pérdida total de la sección del apoyo y anclaje de las lanzas y carencia del elemento lanceado de remate (ejecutado actualmente en madera) hace que se plantee su completa sustitución por nuevos elementos de zinc. Respecto al pico central, su ejecución en fundición hace viable su total saneado y recuperación.

Entre otros problemas y daños de menor prioridad se encuentran el planteamiento de actuaciones para corregir elementos que devalúan el edificio protegido y revalorización de espacios en su imagen interna y externa; así como la eliminación de adiciones improcedentes y elementos cuya presencia se considera 
discordante en el conjunto edificado o en el entorno ${ }^{18}$.

\section{3a PARTE: ACTUACIONES}

Con el fin de dar solución a los problemas planteados, y siguiendo los criterios de prioridad y oportunidad establecidos en la memoria de proyecto, se propuso el siguiente proyecto de intervención.

Los criterios de intervención se centraron en una restauración de acuerdo con las técnicas tradicionales, reintegrando los materiales originales, lo que implica la recuperación de los mismos elementos estructurales y sistemas de anclaje. Se planteó adoptar materiales y cromatismo ya existentes haciendo diferir el tratamiento tecnológico y, por tanto, la imagen final de estos nuevos elementos, que deberán ser coherentes con la técnica aplicada.

Como criterios de actuación frente a humedades procedentes del suelo y subsuelo, se pretende dar salida natural a las aguas para evitar que presionen sobre las fábricas, antes que establecer barreras de defensa sobre éstas. Se proyecta la formación de una cámara de aire ventilada con recogida de aguas en su base, dónde no era posible liberar los muros, evitando tierra sobre los paramentos exteriores de éstos. En el caso del frente al Paseo del Bombé, se corona con sumidero lineal y continuo de recogida de aguas superficiales o de lluvia.

Frente a humedades procedentes de cubierta y zonas altas, manteniendo el mismo material de cobertura, zinc en escamas combinado con planchas en zonas horizontales singulares, se plantea mejorar la disposición constructiva

18 Las adiciones efectuadas en época reciente con el cuerpo adosado de la ampliación del aguaducho del Pavo Real, han sido concebidas sin demasiado rigor, con unas proporciones arquitectónicas que se manifiestan incapaces de facilitar su integración con las demás intervenciones históricas que ponen de manifiesto la evolución del templete musical. Tanto esta deficiente imagen externa que presenta hacia el Paseo de la Herradura, como su deteriorado estado de conservación, obliga a que se analice críticamente su presencia. El traslado inminente de la escuela de hostelería, ubicada en los bajos de dicho pabellón, permitiría acometer sin problemas el desmontaje de esta estructura auxiliar, con la posibilidad de recuperación del primitivo pabellón del Pavo Real y de la fachada primitiva del quiosco de música a este paseo. Se recuperaría de este modo el espacio primitivo de la Herradura. de los faldones y garantizar la estanqueidad en encuentros de la cubierta con los elementos decorativos, ventilación e impermeabilidad de los faldones -mediante la interposición de una lámina impermeable transpirable -. En la cumbrera se plantea colocar, de acuerdo con las soluciones constructivas tradicionales, una lámina de plomo, debido a la poca pendiente $\mathrm{y}$ dado que la cobertura de zinc en este punto se considera insuficiente frente al viento.

El entablado de cubierta se proyecta reponer de acuerdo con las dimensiones y sistema de montaje original, que llevarán tratamiento antifungicida. La madera a emplear será de pino tratado en autoclave, de $\mathrm{PH}$ mayor de 5, compatible con el uso de zinc en cubierta.

Se propone la impermeabilización de los faldones de la cubierta plana que configura la escena, ejecución de junta de dilatación perimetral con los muros de cerramiento de piedra y reposición de solado de baldosa de mosaico hidraúlico artesanal.

Para abordar el problema de degradación de fábricas, cargaderos situados en fachada, eflorescencias en fachada de ladrillo macizo y envejecimiento de morteros en juntas, se proyectan los correspondientes procesos de saneado, limpieza, reparaciones y tratamientos. Se emplearán rejuntados a base de morteros de cal o bastardos, más elásticos y traspirables que los de cemento.

Para la restauración de los elementos de fundición de las barandillas existentes, se hace necesario ejecutar moldes en resina de las piezas de hierro fundido a reproducir. En la ejecución de los roleos decorativos se siguen las mismas fases y/o técnicas de su fundición original. A fin de garantizar una técnica más adecuada a las previsiones actuales se estudió su ejecución por piezas individuales, con introducción en los moldes de unas esperas de acero del mismo diámetro de los redondos. Fundiéndose las piezas de este modo se garantiza una superficie y material apta para la soldadura, y se reduce considerablemente el coste de recuperación por fundición de todo el elemento. Se prevé la sustitución de la pletina del pasamanos, en fundición, de similares características a la existente. 

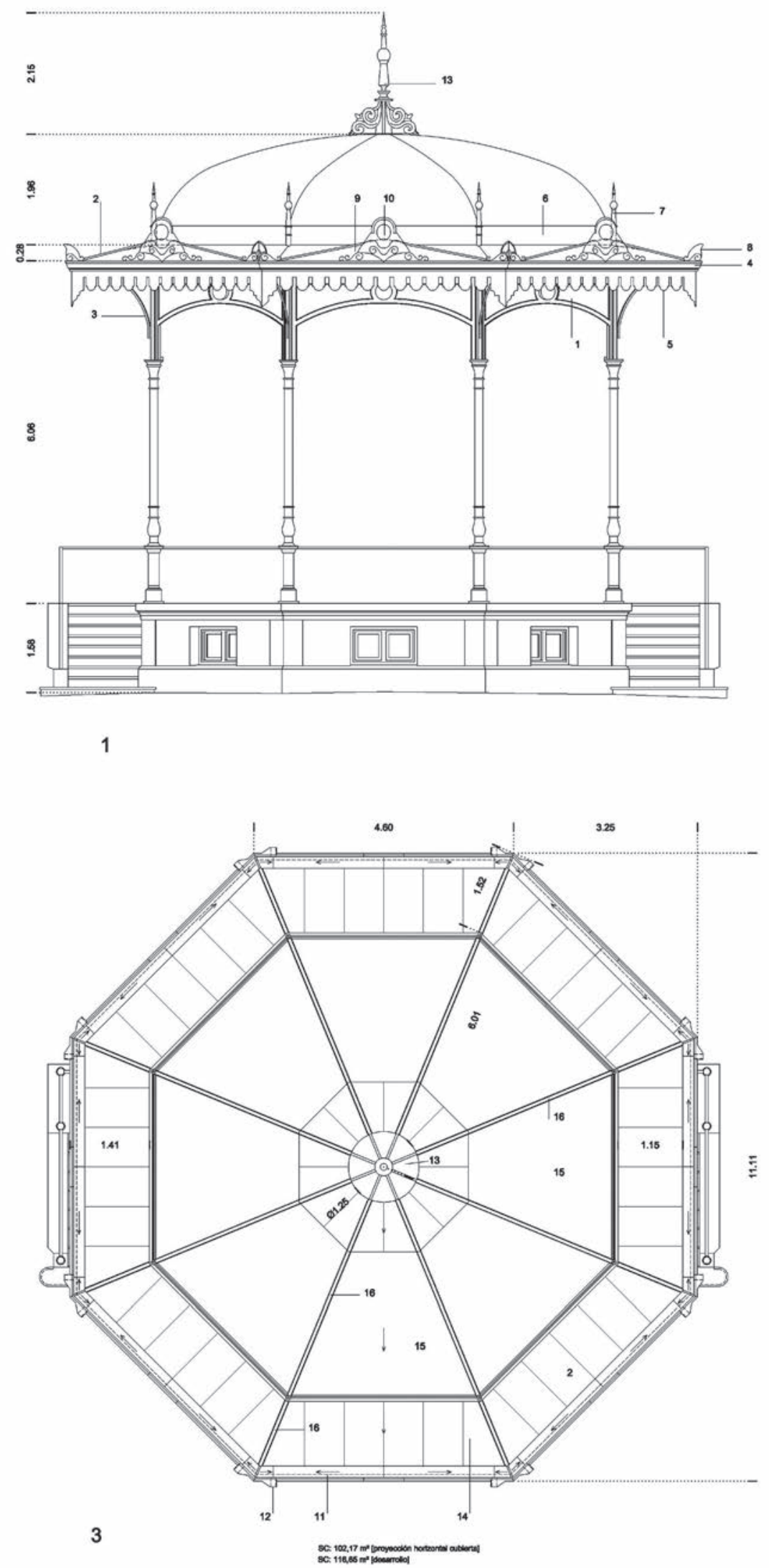

Fig. 17 y 18. Proyecto de Restauración. Clara Rey-Stolle Castro, arquitecto. Alzado al Paseo del Bombé y planta de cubierta. 
Para la ejecución de los elementos metálicos de nervios de cubierta y arriostramientos se hace necesario la obtención de la plantilla de curvado, a partir de las piezas existentes, así como el suministro y curvado en frío de 8 perfiles IPN 120, según dicha curvatura, y 8 perfiles IPN 120 de arriostramiento lateral, preparación de superficie y tratamiento, colocación manual en obra y ejecución de nuevos embonados de madera siguiendo las mismas técnicas de montaje.

Para la restauración de los elementos estructurales de fundición se hace necesario llevar a cabo actuaciones de: desmontaje manual, traslado a taller para su limpieza y reparación, revisión de puntos de anclaje, ménsulas y orejetas. Nueva ejecución de embonado de rosetón y pletinas o forros de enanos según la geometría de las piezas. Aplomado y nivelado de pilares en obra, para posterior montaje de toda la estructura, una vez se hayan restaurado todas las piezas y ejecutado los nuevos elementos metálicos necesarios. Sustitución de tornillos en nudos, mediante tornillería calibrada de alta resistencia. Limpieza y recatado con resinas epoxídicas de toda la superficie de apoyo inferior de las columnas de fundición.

Como sistema de pintado y tratamiento frente a ataques químicos y corrosiones de todos los elementos metálicos, se proyecta limpieza con chorro de arena y tratamiento mediante imprimación epoxi de dos componentes con fosfato de zinc, capa intermedia epoxi modificada de dos componentes, y posterior acabado pintado de poliuretano.

La obra de restauración de la cubierta de zinc, consiste básicamente en la instalación de nuevas bandejas de zinc laminado en la coronación de cubierta, y reemplazo de las escamas de zinc que conforman el acabado visto del resto de la cubierta, manteniendo las características estéticas y constructivas originales. Se propone preservar su artesanía y diseño original, pero incorporando adelantos tecnológicos compatibles. Así las chapas de zinc laminado son del mismo espesor que las originales pero con una aleación de titanio y cobre, que le confiere mayor tenacidad a su componente primario. Se mejora el sistema constructivo clavado original, de los cubre-listones, que se unirán engatillándose.

Previamente al armado de la cubierta, se procede al reemplazo del maderamen y al tratamiento del mismo con productos fungicidas de acción residual. La cara vista de la made- ra se acabará con pintura transpirable de poro abierto.

Respecto a las instalaciones existentes, se hace necesaria la renovación de las instalaciones de electricidad e iluminación, debido al envejecimiento, falta de existencia e inadecuación de las mismas a la normativa vigente. El sistema de iluminación arquitectónico propuesto busca potenciar la relevancia espacial de la cubierta y el templete, así como la creación de un ambiente adecuado para su uso habitual, como escenario de música, y otros posibles usos culturales múltiples que en este espacio se puedan suceder. Para ello se diseña una lámpara suspendida que cuelga a aproximadamente 6 metros de altura, en forma de aro circular, instalada en el centro del espacio, con luminarias de LED orientadas hacia techo y escena. Con esta solución se consigue un efecto parecido al de las lámparas antiguamente utilizadas, o lampadarios.

Respecto a su adecuación con el entorno se plantea la transformación y eliminación del tendido eléctrico aéreo con que se da suministro al Quiosco para las actuaciones que así lo requieran, lo que obliga a la introducción de un cuadro exterior empotrado en el muro perimetral del basamento, bajo la imposta -quedando, por tanto, oculto por las propias líneas arquitectónicas-, que incluya los mecanismos necesarios para garantizar otros usos alternativos. Se introducen igualmente en el proyecto los mecanismos de automatización que permitirían su utilización como iluminación arquitectónica nocturna.

\section{ESTUDIO DE RECUPERACIÓN DEL ALERO Y ELEMENTOS SINGULARES QUE CONFIGURABAN LA CUBIERTA ORIGINAL}

\section{Justificación de la propuesta}

En paralelo a la propuesta de restauración del Quiosco de Música del Bombé, se propone estudiar la recuperación del alero y elementos decorativos superpuestos en zinc, de acuerdo con el diseño original del quiosco, construido en el año 1888, y desmontado por razones que se desconocen.

Como se explica en la memoria de proyecto, dado el alcance de las obras de restauración contenidas en el mismo, con el desmontaje íntegro de la cubierta y actuación integral en la misma, se introduce la necesidad de su estu- 
dio, desde un punto de vista histórico, artístico, cultural, arquitectónico y constructivo, con esta operación de recuperación que contribuiría a: La puesta en valor del elemento arquitectónico del quiosco, mediante la recuperación de elementos del diseño original que lo hacían especialmente atractivo. El respeto y restablecimiento de determinados sistemas constructivos, materiales, compositivos y tipológicos característicos de este tipo de construcciones. La revalorización del espacio en su imagen interna y externa. Y la restitución de un elemento que garantiza la protección y el mantenimiento de toda la estructura del templete ${ }^{19}$, y que se considera, por tanto, indispensable para su conservación. $^{20}$

Para su estudio, se contó con documentación fotográfica de la época, y con el diseño original efectuado por Juan Miguel de la Guardia unos años después en Noreña, a imitación del quiosco de la música de Oviedo; unido al hecho de la aparición de elementos decorativos originales susceptibles de reproducción.

\section{Criterios de intervención:}

Las obras de recuperación del alero, se ejecutarán de acuerdo a la tipología, composición y materiales originales, respetando las características geométricas y constructivas, recogidas en la documentación existente, o en modelos similares de la época, y deberán ser reconocibles. Dada la necesaria conservación de los elementos estructurales originales de fundición, las secciones adoptadas en cubierta se han de adaptar a los encuentros con dichos elementos. Igualmente se ha optado como criterio de conservación y restauración de la estructura mantener, en la medida de lo posible, sus cargas originales sin aumentarlas. El planteamiento de ejecución de los elementos decorativos en zinc, viene de la necesidad de realizarlo en un material ligero que no sobrecargue la estructura existente. El propio proyecto de De la Guardia

19 Ya que, según se detecta de la memoria de diagnóstico, las principales patologías proceden de procesos de corrosión muy avanzados, agravados por la alta exposición de la estructura, sin protección alguna.

20 Se considera, por un lado, una actuación encaminada a la conservación y mejora de sus condiciones de habitabilidad o uso y puesta en valor del edificio, y por ello, englobada dentro de las actuaciones permitidas de acuerdo con la normativa, dada su inclusión como elemento catalogado con la protección Integral Singular. para el quiosco de la música de Oviedo así lo recogía. Su recuperación se proyecta mediante la ejecución de moldes para estampación y el empleo de técnicas tradicionales artesanales de transformación y molduración del zinc, incluida la fundición y el repujado a martillo. Se desechó la ejecución de matrices de hierro o materiales alternativos para la recuperación de las piezas mediante estampación industrial, por el elevado coste de las mismas.

Se pretendió resolver las cuestiones constructivas deficientes detectadas, como garantizar la durabilidad de estos elementos de estampación, o la dificultad que podía presentar en el diseño original la evacuación de agua de lluvia, procedente del plano de cubierta.

Sistema constructivo planteado en el alero del quiosco de música de Oviedo:

La estructura o batidor que recibe el tablazón de madera del faldón del alero, se resuelve mediante ménsulas estructurales en el sentido de los radios del octógono desde el enano al borde y perfil estructural de borde. La tabla de madera aparece vista, igual que en la formación de la cubierta abovedada, como acabado inferior del alero. Sobre dicho tablero se proyecta un segundo entarimado de madera de idénticas características sobre rastreles, que modifica la pendiente adaptándola a las necesidades de evacuación de agua de la misma y permite la construcción del canal de borde; con acabado de chapa lisa de zinc de $6 \mathrm{~mm}$ de espesor con interposición de lámina impermeable transpirable sobre lámina drénate y formación de canalón oculto en su desarrollo perimetral.

La ejecución de los elementos decorativos de la ménsula se proyecta según el mismo sistema constructivo planteado en la recuperación de las barandillas de fundición, con la realización de los moldes de las piezas ornamentales de hierro fundido, en resina, según modelos existentes en las propias celosías del quiosco.

Recuperación de elementos decorativos originales en zinguería ornamental:

Se trata de la recuperación de motivos ornamentales de cornisas, acroteras y adornos de origen clásico, realizados en zinc transformado mediante diferentes técnicas de cilindrado, y procesos tradicionales de martillado, estampado, repujado y/o moldurado propios del año 
1888, que comprende la recuperación de los siguientes elementos:

- Cornisa con perfil estampado de remate exterior mediante pieza de zinc moldurada de borde, que constituya el remate visto del faldón del alero de zinc, ejecutada siguiendo un diseño similar al original, presente actualmente en el quiosco de música de Noreña.

- Cada extremo del octógono se decora con una acrotera de motivos vegetales o remate en esquina. Se trata de los mismos motivos existentes en el Quiosco de Noreña, realizados aquí en zinc. Se plantea su ejecución mediante la obtención in situ de un modelo de silicona, que se modifica incorporando en su diseño las gárgolas de zinc, para evacuación de agua de cubierta.

- Lambrequín estampado, de acabado inferior de remate del alero, y cresta doble estampada que unía las lanzas. Elementos perdidos en ambos quioscos, de los que solamente tenemos los detalles de fotografías históricas y la referencia documental del proyecto original.

- Frontón o sección triangular dispuesto sobre el entablamento o cornisa, rematando cada lado del alero: realizado en doble chapa de zinc, con superposición de elementos decorativos y molduras. La rigidización del frontón decorativo se plantea mediante pletinas y varillas de hierro ocultos en el alero ${ }^{21}$.

- Acroteras con cara estampada en medallón central y roleos decorativos, como elementos decorativos centrales del tímpano de dicho frontón. Durante la redacción del presente proyecto se ha localizado una acrotera central del frontón, conservada en los almacenes del Ayuntamiento, hecho que hace viable su posible reproducción. Se trata de una pieza ejecutada en hierro fundido, por lo que suponemos que la totalidad del alero se ejecutó, en contra de los datos del proyecto, en hierro fundido. $\mathrm{Su}$ desmontaje posterior obedecería, según este supuesto, a su excesivo sobrepeso debido a las dimensiones y al material empleado.

21 Para las estructuras verticales de frontones y tímpanos se proyecta una estructura auxiliar en acero y enrastrelado o forro de madera, sobre la que se colocarían las planchas lisas de zinc.
- Lanzas decorativas: en diseño similar a las originales, de aproximadamente $1,20 \mathrm{~m}$ de altura al exterior.

\section{Bibliografía}

CABEZAS, Juan Antonio. “Asturias. Biografía de una región”. Espasa-Calpe S.A. Madrid, 1956.

CANELLA Y SECADES, Fermín. El libro de Oviedo. Oviedo: Ayuntamiento, 1887.

CASAPRIMA COLLERA, Adolfo. El Campo de los Hombres Buenos (Historia del Parque de San Francisco de Oviedo). 1996.

FANJUL CABEZA, José Manuel. "Datos históricos del concejo de Noreña"

NAVASCUÉS PALACIO, Pedro. Arquitectura e ingeniería del hierro en España (18141936). Fundación Iberdrola. Ediciones el Viso, 2007.

MORALES SARO, Ma Cruz. "El Modernismo en Asturias”. Arquitectura, escultura y artes decorativas".

SANTANA, Juan. "El Ayer de Oviedo en fotos". Gráficas EUJOA, S.A. 1987.

TOLIVAR FAES, José. Nombres y Cosas de las Calles de Oviedo 1992. Oviedo: Ayuntamiento, 1992.

TOMÉ, Sergio. La formación de la ciudad burguesa 1850-1950" Oviedo: COAA, 1988.

“Artistas Asturianos". "Juan Miguel de la Guardia”, María Cruz Morales Saro. Hércules Astur de Ediciones, Oviedo, 2002.

Guia de Arquitectura y Urbanismo de la Ciudad de Oviedo. Oviedo: COAA, 1998.

Oviedo 1753: Según las Respuestas Generales del Catastro de Ensenada. Madrid: Ed. Tabapress, 1990.

"La arquitectura del hierro en Asturias", J.R. Fernández Molina, J. González Moriyón. C.O.A.A., Oviedo, 1994. 